Article

\title{
Prominent Conductor Mechanism-Induced Electron Transfer of Biochar Produced by Pyrolysis of Nickel-Enriched Biomass
}

\author{
Wenbing Tan ${ }^{1,2,+}$, Renfei Li ${ }^{1,2,+}$, Hanxia Yu ${ }^{3}$, Xinyu Zhao ${ }^{1,2}$, Qiuling Dang ${ }^{1,2}$, Jie Jiang ${ }^{4}$, \\ Lei Wang ${ }^{1,2, *}$ and Beidou $\mathrm{Xi}^{1,2, *}$ \\ 1 State Key Laboratory of Environmental Criteria and Risk Assessment, Chinese Research Academy of \\ Environmental Sciences, Beijing 100012, China; wenbingtan@126.com (W.T.); lirenfei1114@163.com (R.L.); \\ zhaoxinyu1126@126.com (X.Z.); dangling819@126.com (Q.D.) \\ 2 State Environmental Protection Key Laboratory of Simulation and Control of Groundwater Pollution, \\ Chinese Research Academy of Environmental Sciences, Beijing 100012, China \\ 3 School of Life Sciences, South China Normal University, Guangzhou 510631, China; yhanxia@126.com \\ 4 College of Environmental Science and Engineering, Beijing Forestry University, Beijing 100083, China; \\ jiangjie@bjfu.edu.cn \\ * $\quad$ Correspondence: wangleicraes@163.com (L.W.); wbtann@126.com (B.X.); Tel.: +86-10-8491-3133 (B.X.) \\ + These authors contributed equally to this work.
}

Received: 7 October 2018; Accepted: 15 November 2018; Published: 22 November 2018

\begin{abstract}
Biochar is redox-active and can function as a sustainable electron shuttle in catalyzing relevant redox reactions. It plays a crucial role in environmental remediation. In this work, we used different-nickel (Ni)-level biochars produced by the pyrolysis of plant biomass with correspondingly different Ni levels as extracellular electron shuttles for microbial reduction of ferrihydrite by Shewanella oneidensis MR-1. A high Ni level of the precursor considerably enhanced the conductor mechanism of the produced biochar and thus enabled the biochar to catalyze increased microbial reductions of the $\mathrm{Fe}(\mathrm{III})$ mineral, but it did not promote the charging and discharging capacities of the produced biochar. This study can aid in the search for natural biomass with high Ni content to establish low-cost biochars with wide-ranging applications in catalyzing the redox-mediated reactions of pollutants.
\end{abstract}

Keywords: biochar; Ni-rich biomass; microbial reduction; electron transfer; conductor mechanism; redox mechanism

\section{Introduction}

Biochar is a highly aromatized refractory solid polymer produced from the thermal decomposition of diverse biomass species under completely or partially anaerobic conditions [1]. In the past few years, the great application potential of biochar has elicited increasing attention. Research has demonstrated that biochar plays crucial roles in plant growth, pollutant removal, catalytic reactions, energy storage, $\mathrm{CO}_{2}$ capture, and climate warming mitigation [1]. The eco-environmental effects of biochar are attributed to its special physical and chemical properties, including $\mathrm{pH}$, nutrient element composition, surface functional groups, microporous structure, specific surface area, sorption performance, and recalcitrance against degradation [2]. Recent studies have revealed that biochar has a new, potentially significant function. A study has shown that biochar is redox-active and can reversibly accept and donate electrons [3], which is crucial in catalyzing relevant redox reactions. The redox-active property of biochar is mirrored by its redox and conductor mechanisms [3,4]. The redox mechanism of biochar involves the electron flux through charging and discharging cycles of surface functional 
groups, and the conductor mechanism of biochar involves electron transfer through its conductive domains [5].

The demand for mineral resources is increasing due to the development of the global economy. Nickel (Ni), as a strategic material, has ignited a wave of development of mineral resources and $\mathrm{Ni}$ production at a global scale. However, the number of contaminated sites caused by Ni continues to increase. How to remediate these contaminated fields and how to effectively utilize $\mathrm{Ni}$ are serious problems. $\mathrm{Ni}$ is a transition metal element with high electrical conductivity. However, whether the Ni-rich characteristic of biochar can enhance its conductor mechanism or not remains unknown. Although Ni-doping modification techniques can increase the content of $\mathrm{Ni}$ in biochars, $\mathrm{Ni}$ is only doped on the surface of biochars, and Ni-doping requires a series of specialized processes. Hence, $\mathrm{Ni}$-rich biochars may not provide an ideal conductor mechanism, and expensive economic costs are required. Pyrolysis that uses Ni-enriched biomass directly may be a preferred method for producing Ni-rich biochars. Given that biochars produced by the pyrolysis of a Ni-enriched biomass exhibit an improved conductor mechanism, producing biochars through the pyrolysis of Ni-enriched biomass not only promotes the functionality of biochars but also turns Ni from waste and ferronickel mine land into valuable resources via the bioaccumulation of $\mathrm{Ni}$ in plant biomass.

In this study, we used different Ni-level biochars produced by the pyrolysis of plant roots with correspondingly different Ni levels as extracellular electron shuttles for catalyzing the microbial reduction of ferrihydrite by Shewanella oneidensis MR-1. The main goal of this study was to test whether the biochar produced by the pyrolysis of a Ni-enriched biomass exhibits an improved conductor mechanism or not. The results of the present study can promote the application of biochars from Ni-rich-biomass pyrolysis for the control of redox-active pollutants.

\section{Results and Discussion}

Abiotic controls with biochar and ferrihydrite showed that biochar did not provide a considerable contribution to the reduction of Fe(III) mineral ferrihydrite to Fe(II) within $72 \mathrm{~h}$ (Figure 1A). When S. oneidensis MR-1 was incubated with lactate and ferrihydrite, we observed about $50 \%$ of $\mathrm{Fe}(\mathrm{II})$ formation within $72 \mathrm{~h}$ (Figure 1A), which is consistent with fact that S. oneidensis MR-1 can reduce $\mathrm{Fe}(\mathrm{III})$ minerals to soluble $\mathrm{Fe}(\mathrm{II})$ in the environment through direct-contact mechanisms. When biochars were added to $S$. oneidensis MR-1 inoculated with ferrihydrite and lactate, the Fe(II) formation rates and extents increased remarkably beyond the additive values of biochar with ferrihydrite and S. oneidensis MR-1 with ferrihydrite, respectively (Figure 1A). This result indicates that biochar can catalyze extracellular electron shuttle by transferring electrons from S. oneidensis MR-1 to Fe(III) mineral ferrihydrite. Notably, the Fe(II) formation rates and extents in the presence of cells and biochars increased gradually with increasing Ni levels in the biochars (Figure 1A,B), suggesting that the effect of biochars on the microbial reduction of ferrihydrite by S. oneidensis MR-1 was dependent on the Ni level.

Biochar, through its redox and conductor mechanisms, has been utilized to transfer electrons from cells to Fe(III) mineral [6]. The redox mechanism of biochar in shuttling electrons is positively dependent on the charging and discharging capacities of its surface redox-active functional groups [5]. In this study, biochar suspensions were subjected to microbial reduction for $72 \mathrm{~h}$ by $S$. oneidensis MR-1 and subsequent sterilization through ultraviolet radiation. After these suspensions were added to ferrihydrite, biochars with different Ni levels did not significantly differ in catalyzing the reduction of ferrihydrite to Fe(II) (Figure 1B). This result can be attributed to the identical distributions of the redox-active groups on the surfaces of the biochars with different $\mathrm{Ni}$ levels. The increased Fe(II) formation rates and extents in the presence of cells and biochars with increasing Ni levels in the biochars can be attributed to the high contact performance of Ni-rich biochars with cells and ferrihydrite. However, our results also showed that biochars with relatively high Ni levels did not exhibit high physicochemical parameters (e.g., surface area, pore structure, particle size, and $\mathrm{pH}$ ) that governed 
their adsorption performance (Table 1). This result suggests that the biochars with different Ni levels did not considerably differ in their contact performance with cells and ferrihydrite.
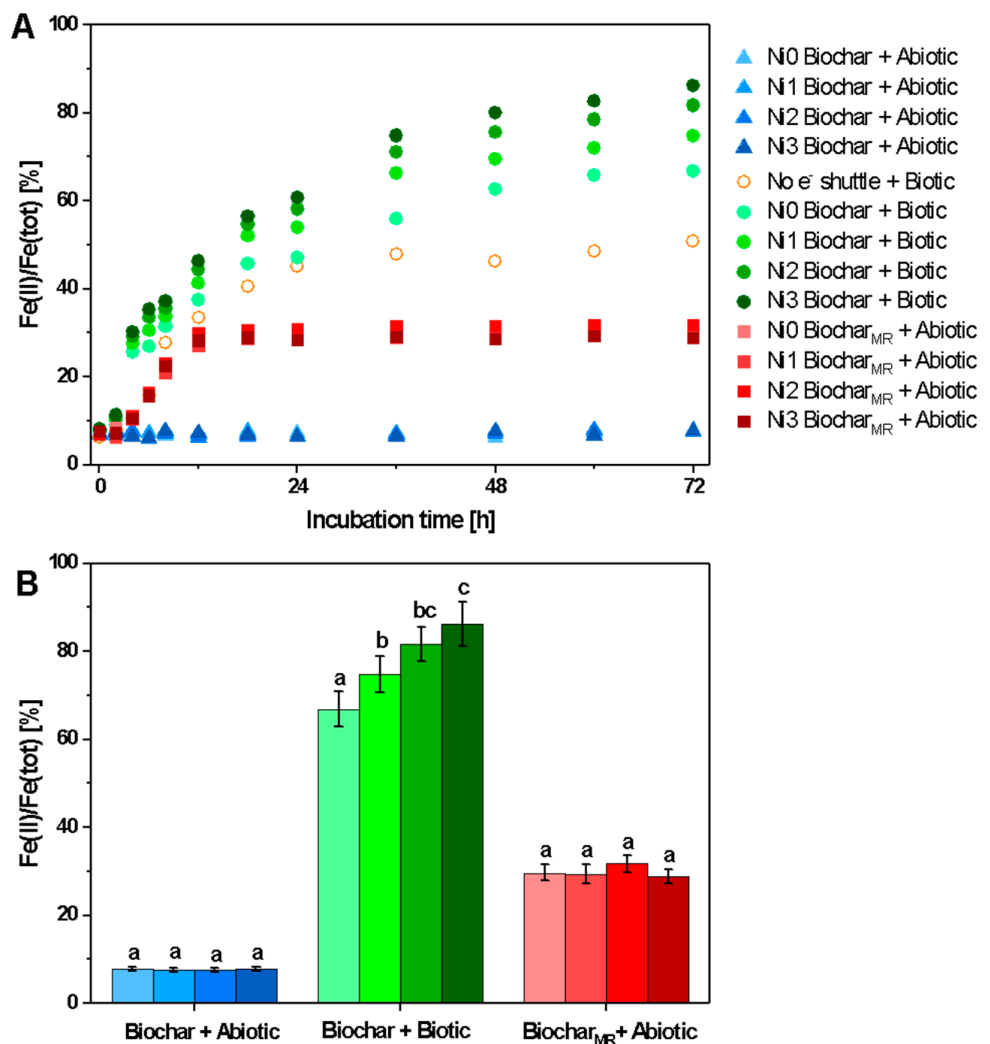

Figure 1. Reduction of ferrihydrite by S. oneidensis MR-1. (A) Formation curves of Fe(II) in bottles amended with different Ni-level biochars. (B) Fe(II) formation in bottles amended with different Ni-level biochars within $72 \mathrm{~h}$. "Biotic" and "abiotic" indicate setups with and without MR-1 cells added, respectively. "Biochar ${ }_{M R}$ " indicates biochar after $72 \mathrm{~h}$ of microbial reduction by S. oneidensis MR-1. Ni0, Ni1, Ni2, and Ni3 indicate $0.09 \mathrm{~g} \mathrm{~kg}^{-1}, 494 \mathrm{~g} \mathrm{~kg}^{-1}, 1156 \mathrm{~g} \mathrm{~kg}^{-1}$ and $1641 \mathrm{~g} \mathrm{~kg}^{-1}$, respectively, of $\mathrm{Ni}$ in biochars (See Table 1). In (B), means followed by the same lowercase letter for each setup are not significantly different at $p<0.05$ ( $t$-test).

Table 1. Physicochemical properties of biochars with different Ni contents. Mean $( \pm S E, n=3)$.

\begin{tabular}{ccccc}
\hline Parameter & Ni0 & Ni1 & Ni2 & Ni3 \\
\hline $\mathrm{C}(\%)$ & $56.1 \pm 4.2$ & $63.6 \pm 4.4$ & $58.2 \pm 3.9$ & $60.4 \pm 4.0$ \\
$\mathrm{H}(\%)$ & $4.0 \pm 0.3$ & $3.8 \pm 0.3$ & $3.4 \pm 0.2$ & $4.0 \pm 0.3$ \\
$\mathrm{~N}(\%)$ & $1.9 \pm 0.2$ & $2.3 \pm 0.2$ & $1.8 \pm 0.2$ & $2.1 \pm 0.2$ \\
$\mathrm{O}(\%)$ & $22.8 \pm 3.1$ & $27.8 \pm 2.2$ & $22.3 \pm 2.7$ & $28.4 \pm 2.4$ \\
$\mathrm{P}(\%)$ & $0.4 \pm 0.1$ & $0.4 \pm 0.1$ & $0.4 \pm 0.1$ & $0.3 \pm 0.1$ \\
$\mathrm{~K}(\%)$ & $1.2 \pm 0.2$ & $1.0 \pm 0.1$ & $1.1 \pm 0.2$ & $1.1 \pm 0.1$ \\
$\mathrm{Ca} \mathrm{( \% )}$ & $9.2 \pm 0.6$ & $8.8 \pm 0.6$ & $8.9 \pm 0.6$ & $8.7 \pm 0.6$ \\
$\mathrm{Mg} \mathrm{( \% )}$ & $6.2 \pm 0.5$ & $5.7 \pm 0.6$ & $6.3 \pm 0.5$ & $5.8 \pm 0.6$ \\
$\mathrm{Fe}\left(\mathrm{mg} \mathrm{kg}^{-1}\right)$ & $615 \pm 42$ & $576 \pm 38$ & $591 \pm 44$ & $584 \pm 37$ \\
$\mathrm{Co}\left(\mathrm{mg} \mathrm{kg}^{-1}\right)$ & $1.3 \pm 0.1$ & $1.4 \pm 0.2$ & $1.2 \pm 0.1$ & $1.3 \pm 0.2$ \\
$\mathrm{Cu}\left(\mathrm{mg} \mathrm{kg}^{-1}\right)$ & $25.1 \pm 2.2$ & $25.8 \pm 3.3$ & $28.5 \pm 2.5$ & $27.1 \pm 3.6$ \\
$\mathrm{Zn}\left(\mathrm{mg} \mathrm{kg}^{-1}\right)$ & $16.6 \pm 1.1$ & $15.9 \pm 1.5$ & $17.4 \pm 1.3$ & $15.4 \pm 1.4$ \\
$\mathrm{Mo}\left(\mathrm{mg} \mathrm{kg}^{-1}\right)$ & $0.3 \pm 0.1$ & $0.4 \pm 0.1$ & $0.3 \pm 0.1$ & $0.4 \pm 0.1$ \\
$\mathrm{Ni}\left(\mathrm{mg} \mathrm{kg}^{-1}\right)$ & $0.09 \pm 0.01$ & $494 \pm 58$ & $1156 \pm 159$ & $1641 \pm 179$ \\
$\mathrm{pH}$ & $8.5 \pm 0.1$ & $8.4 \pm 0.3$ & $8.7 \pm 0.1$ & $8.5 \pm 0.3$ \\
$\mathrm{Ash}(\%)$ & $21.8 \pm 1.5$ & $20.2 \pm 2.1$ & $21.4 \pm 1.5$ & $23.1 \pm 2.1$ \\
Surface area $\left(\mathrm{m}^{2} \mathrm{~g}^{-1}\right)$ & $295 \pm 22$ & $298 \pm 34$ & $313 \pm 26$ & $222 \pm 37$ \\
\hline
\end{tabular}

Note: $\mathrm{Ni}$, Ni1, Ni2, and Ni3 indicate different Ni contents of biochars from iris roots with different Ni contents (see Table 2). 
Altogether, these results indicate that the $\mathrm{Ni}$ level of the biochar stimulated the electron transfer from cells to ferrihydrite by improving the conductor mechanism of the biochar (Figure 2). Analogous to the electron-carrying heme in the outer-membrane cytochromes of microorganisms $[7,8]$, the abundance of $\mathrm{Ni}$ in the biochars formed an electron transfer conduit that promoted the direct transfer of electrons. This phenomenon may have increased the conductor mechanism of the biochars and thus catalyzed the microbial reduction of Fe(III) mineral ferrihydrite to Fe(II). In order to pinpoint the detailed mechanisms of the effects of Ni level of the biochar on its conductor mechanism, future investigation is needed to clarify the oxidation states of $\mathrm{Ni}$ species through X-ray Photoelectron Spectroscopy (XPS) analysis, and to evaluate the surface potential, particle size distribution, and residual groups through Boehm testing.

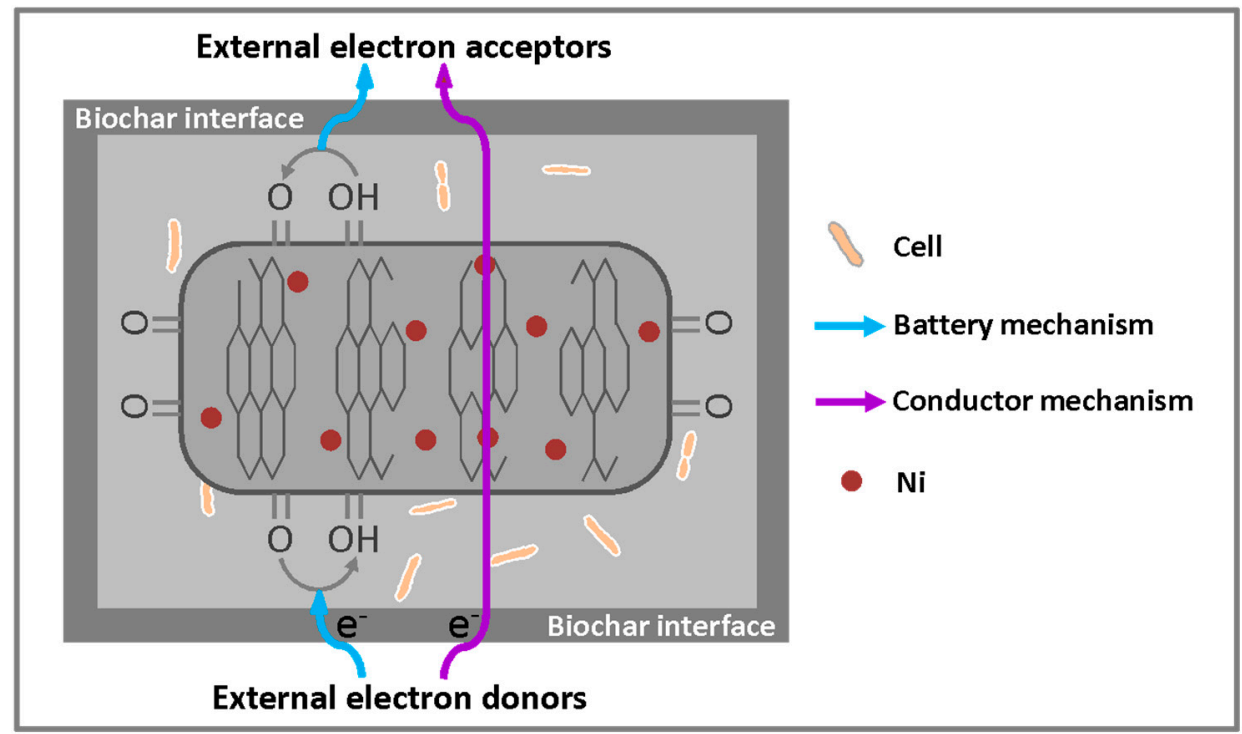

Figure 2. Schematic diagram of the biochar-internal pathways for electron transfer mediated by biochar.

Considering the positive association of the catalyzed effectiveness of biochars in the microbial reduction of $\mathrm{Fe}(\mathrm{III})$ minerals through their conductor and redox mechanisms, we expect the produced biochars to be rapid in directly transferring electrons and in the charging and discharging cycles of their surface redox-active functional groups. A study has demonstrated that the low $\mathrm{H} / \mathrm{C}$ and $\mathrm{O} / \mathrm{C}$ ratios of biochars enhance the conductor mechanism [5] by which electrons can be directly and rapidly transferred from cells to the terminal electron acceptors. Although the features of the elemental composition of biochars can be fine-tuned by adjusting the pyrolysis conditions (e.g., heating rate and temperature) $[9,10]$, this study revealed that a high Ni level of the precursor can remarkably enhance the conductor mechanism of the produced biochars. Thus, future efforts should focus on the search for natural plants with high capacities to absorb Ni. Such plants can be used not only to remove $\mathrm{Ni}$ from Ni-contaminated environmental matrices through phytoremediation, but also to promote the wide application of biochars in environmental remediation through their prominent conductor mechanism-induced electron transfer functionality.

\section{Materials and Methods}

\subsection{Preparation of Biochar}

To uniformly load Ni into the internal structure of biochar rather than doping $\mathrm{Ni}$ on its surface, a Ni-loaded iris (Iris sibirica L.) was cultivated through a Ni-added hydroponic method. At the beginning of the cultivation, irises (six months of growth, same weight; Daxing nursery, Beijing, China) were randomly divided into four groups, and each group contained three plants. Each group was then placed in a bucket filled with $10 \mathrm{~L}$ of nutrient solution. The nutrient solution contained $5.0 \mathrm{mmol}$ of 
$\mathrm{KNO}_{3}, 5.0 \mathrm{mmol}$ of $\mathrm{Ca}\left(\mathrm{NO}_{3}\right)_{2} \cdot 4 \mathrm{H}_{2} \mathrm{O}, 1.0 \mathrm{mmol}$ of $\mathrm{KH}_{2} \mathrm{PO}_{4}, 2.0 \mathrm{mmol}$ of $\mathrm{MgSO}_{4} \cdot 7 \mathrm{H}_{2} \mathrm{O}, 9.0 \mathrm{mmol}$ of $\mathrm{MnCl}_{2} \cdot 4 \mathrm{H}_{2} \mathrm{O}, 0.8 \mathrm{mmol}$ of $\mathrm{ZnSO}_{4} \cdot 7 \mathrm{H}_{2} \mathrm{O}, 0.3 \mathrm{mmol}$ of $\mathrm{CuSO}_{4} \cdot 5 \mathrm{H}_{2} \mathrm{O}, 4.0 \mathrm{mmol}$ of $\mathrm{H}_{3} \mathrm{BO}_{3}, 0.01 \mathrm{mmol}$ of $\mathrm{H}_{2} \mathrm{MoO}_{4} \cdot \mathrm{H}_{2} \mathrm{O}$ and $0.8 \mathrm{mmol} \mathrm{Fe} 2\left(\mathrm{SO}_{4}\right)_{3}$ citrate as the iron source. The experiment was conducted in a greenhouse, and the temperature was maintained from $21.0^{\circ} \mathrm{C}-28.0^{\circ} \mathrm{C}$. The average photoperiod was $15 \mathrm{~h}$ light $/ 9 \mathrm{~h}$ dark. After two weeks of cultivation, $\mathrm{Ni}$ was added to the nutrient solutions with concentration gradients of $0,25.00,100.00$, and $300.00 \mathrm{mg} \mathrm{L}^{-1}$. Experiments were conducted in triplicate for each Ni level. Deionized water was added to maintain a constant volume of the solution every day, and the nutrient solutions were completely replaced every week. The plants were harvested after two months of Ni-added cultivation. The element contents of the iris roots are shown in Table 2. Note that all the chemicals used in this study were purchased from Sinopharm Chemical Reagent Co., Ltd. (Shanghai, China).

Table 2. Element contents of the iris roots obtained from plots with different Ni levels added. Mean $( \pm \mathrm{SE}, \mathrm{n}=3)$.

\begin{tabular}{|c|c|c|c|c|}
\hline & \multicolumn{4}{|c|}{ Ni Levels in Nutrient Solutions } \\
\hline & Control (Ni0) & $25 \mathrm{mg} \mathrm{L}^{-1}(\mathrm{Ni1})$ & $100 \mathrm{mg} \mathrm{L}^{-1}(\mathrm{Ni} 2)$ & $300 \mathrm{mg} \mathrm{L}^{-1}(\mathrm{Ni} 3)$ \\
\hline $\mathrm{Ni}\left(\mathrm{mg} \mathrm{kg}^{-1}\right)$ & $0.003 \pm 0.000$ & $11.5 \pm 1.3$ & $26.9 \pm 2.3$ & $39.4 \pm 3.6$ \\
\hline $\mathrm{C}\left(\mathrm{g} \mathrm{kg}^{-1}\right)$ & $462 \pm 39$ & $418 \pm 40$ & $452 \pm 37$ & $437 \pm 43$ \\
\hline $\mathrm{N}\left(\mathrm{g} \mathrm{kg}^{-1}\right)$ & $29.6 \pm 3.01$ & $34.6 \pm 2.7$ & $33.5 \pm 2.9$ & $34.1 \pm 2.6$ \\
\hline $\mathrm{H}\left(\mathrm{g} \mathrm{kg}^{-1}\right)$ & $42.9 \pm 4.3$ & $38.3 \pm 3.1$ & $44.5 \pm 4.0$ & $37.2 \pm 3.6$ \\
\hline $\mathrm{O}\left(\mathrm{g} \mathrm{kg}^{-1}\right)$ & $329 \pm 29.8$ & $317 \pm 25$ & $314 \pm 29$ & $297 \pm 25$ \\
\hline
\end{tabular}

Biochar was prepared by pyrolyzing $\left(600^{\circ} \mathrm{C}, 2 \mathrm{~h}\right)$ the roots of Ni-loaded irises in an air-starved environment. Given that $600^{\circ} \mathrm{C}$ is a relatively low temperature to achieve the conductivity of biochar, the choice of $600{ }^{\circ} \mathrm{C}$ can effectively verify whether the biochar produced by the pyrolysis of the $\mathrm{Ni}$-enriched biomass can improve the conductor mechanism. After being cut into slices, the roots were pretreated with $1 \mathrm{M}$ of $\mathrm{NaOH}$ solution to remove the impurities on their surfaces, rinsed to neutral with deionized water, and dried at $105^{\circ} \mathrm{C}$. The biochar obtained after pyrolysis was used without further modification.

\subsection{Biochar Characterization}

Carbon $(\mathrm{C})$, nitrogen $(\mathrm{N})$, hydrogen $(\mathrm{H})$, and oxygen $(\mathrm{O})$ contents were determined with a high-temperature automated elemental analyzer (Vario EL cube, Langenselbold, Germany). The iron $(\mathrm{Fe})$, phosphorus $(\mathrm{P})$, potassium $(\mathrm{K})$, calcium $(\mathrm{Ca})$, magnesium $(\mathrm{Mg})$, cobalt $(\mathrm{Co})$, copper $(\mathrm{Cu})$, zinc ( $\mathrm{Zn})$, molybdenum (Mo), and nickel (Ni) of biochars were extracted by aqua regia at $160{ }^{\circ} \mathrm{C}$ and then determined via inductively coupled plasma-optical emission spectrometry (ICP-OES, Thermo ICAP-6000, Madison, WI, USA). $\mathrm{pH}$ was measured in deionized water at a ratio of 1:5 w/w. The surface area and ash content of biochars were determined following the method of Mukherjee et al. [11]. The electrical conductivity of biochar was measured by adopting the method of Wiedner et al. [12].

\subsection{Microorganisms and Biochar Suspensions}

The microorganisms and anoxic biochar suspensions were prepared according to the procedure of Kappler et al. [6]. For the microorganism suspensions, S. oneidensis MR-1 was cultured according to the method in a previous study [13]. The culture was centrifuged after incubation in LB medium for $24 \mathrm{~h}$. Then, the cell pellet was washed four times with $30 \mathrm{mM}$ of anoxic bicarbonate buffer $(\mathrm{pH}=7)$ and suspended at a density of $10^{10}$ cells $\mathrm{mL}^{-1}$.

After one night of deoxygenation, powdered biochar was suspended in anoxic water to a final concentration of $150 \mathrm{~g} \mathrm{~L}^{-1}$. The suspension was dispersed using an ultrasonic probe for $10 \mathrm{~min}$, degassed under vacuum for $2 \mathrm{~min}$, rinsed with $\mathrm{N}_{2}$ for $5 \mathrm{~min}$, and sterilized using an autoclave $\left(120^{\circ} \mathrm{C}\right.$, $20 \mathrm{~min})$. 


\subsection{Ferrihydrite Reduction Experiments}

Ferrihydrite reduction assays were set up in triplicate in serum bottles containing $10 \mathrm{~mL}$ of $30 \mathrm{mM}$ $\mathrm{NaHCO}_{3}$ buffer $(\mathrm{pH}=7)$, sodium lactate $(30 \mathrm{mM}), 15 \mathrm{mM}$ ferrihydrite, biochar (final concentration of $\left.5 \mathrm{~g} \mathrm{~L}^{-1}\right)$, and S. oneidensis MR-1 cells $\left(10^{9}\right.$ cells $\left.\mathrm{mL}^{-1}\right)$. Anoxic water was added as a control. Approximately $100 \mu \mathrm{L}$ of the solution was extracted with $900 \mu \mathrm{L}$ of $1 \mathrm{M} \mathrm{HCl}(1 \mathrm{~h})$ to determine the total $\mathrm{Fe}(\mathrm{II})$ and total Fe concentrations at predetermined time intervals.

Ferrozine assay was used to quantify Fe(II) and Fe(III). Briefly, a total of $200 \mu \mathrm{L}$ of the reaction mixture was added to $5 \mathrm{~mL}$ of $50 \mathrm{mM}$ HEPES-buffered ferrozine $\left(1 \mathrm{~g} \mathrm{~L}^{-1}\right)$ solution. Absorbance was measured immediately with an ultraviolet-visible spectrophotometer (Shimadzu UV-1800, Tokyo, Japan) at $510 \mathrm{~nm}$.

\section{Conclusions}

Overall, the results demonstrated that a high $\mathrm{Ni}$ level of the precursor considerably enhanced the conductor mechanism of the produced biochars and thus enabled the biochars to catalyze increased microbial reductions of $\mathrm{Fe}(\mathrm{III})$ minerals, but it did not promote the charging and discharging capacities of the produced biochars. This study provided insights into the role of biochars produced by the pyrolysis of Ni-enriched biomass in catalyzing relevant redox reactions.

Author Contributions: W.T. and B.X. conceived and designed the experiments; R.L. and H.Y. performed the experiments; W.T., H.Y. and L.W. analyzed the data with suggestions by X.Z., Q.D. and J.J.; W.T. and R.L. wrote the paper; J.J., L.W. and B.X. proofed the paper.

Funding: This research was funded by the National Natural Science Foundation of China (Project Nos. 41501242 and 51325804), the Central Level Scientific Research Institutes for basic R\&D special fund business (2014-GZ-006), and the Beijing advanced innovation Center for Future Urban Design of Beijing University of Civil Engineering and Architecture (UDC 2017032512).

Acknowledgments: We thank Liang Zhao, Xiangxue Zhang and Zhanglan Liu for assistance in the laboratory and with data analysis, and the editor and three anonymous reviewers for their insightful comments that greatly improved this manuscript.

Conflicts of Interest: The authors declare that they have no conflict of interest.

\section{References}

1. Oliveira, F.R.; Patel, A.K.; Jaisi, D.P.; Adhikari, S.; Lu, H.; Khanal, S.K. Environmental application of biochar: Current status and perspectives. Bioresour. Technol. 2017, 246, 110-122. [CrossRef] [PubMed]

2. Liu, W.; Jiang, H.; Yu, H. Development of biochar-based functional materials: Toward a sustainable platform carbon material. Chem. Rev. 2015, 115, 12251-12285. [CrossRef] [PubMed]

3. Yuan, Y.; Bolan, N.; Prévoteau, A.; Vithanage, M.; Biswas, J.K.; Ok, Y.S.; Wang, H. Applications of biochar in redox-mediated reactions. Bioresour. Technol. 2017, 246, 271-281. [CrossRef] [PubMed]

4. Saquing, J.M.; Yu, Y.; Chiu, P.C. Wood-derived black carbon (biochar) as a microbial electron donor and acceptor. Environ. Sci. Technol. 2016, 3, 62-66. [CrossRef]

5. Sun, T.; Levin, B.D.; Guzman, J.J.; Enders, A.; Muller, D.A.; Angenent, L.T.; Lehmann, J. Rapid electron transfer by the carbon matrix in natural pyrogenic carbon. Nat. Commun. 2017, 8, 14873. [CrossRef] [PubMed]

6. Kappler, A.; Wuestner, M.L.; Ruecker, A.; Harter, J.; Halama, M.; Behrens, S. Biochar as an electron shuttle between bacteria and Fe(III) minerals. Environ. Sci. Technol. 2014, 1, 339-344. [CrossRef]

7. Okamoto, A.; Hashimoto, K.; Nealson, K.H.; Nakamura, R. Rate enhancement of bacterial extracellular electron transport involves bound flavin semiquinones. Proc. Natl. Acad. Sci. USA 2013, 110, 7856-7861. [CrossRef] [PubMed]

8. Richardson, D.J.; Butt, J.N.; Clarke, T.A. Controlling electron transfer at the microbe-mineral interface. Proc. Natl. Acad. Sci. USA 2013, 110, 7537-7538. [CrossRef] [PubMed]

9. Cimò, G.; Kucerik, J.; Berns, A.E.; Schaumann, G.E.; Alonzo, G.; Conte, P. Effect of heating time and temperature on the chemical characteristics of biochar from poultry manure. J. Agric. Food Chem. 2014, 62, 1912-1918. [CrossRef] [PubMed] 
10. McBeath, A.V.; Smernik, R.J.; Krull, E.S.; Lehmann, J. The influence of feedstock and production temperature on biochar carbon chemistry: A solid-state ${ }^{13} \mathrm{C}$ NMR study. Biomass Bioenergy 2014, 60, 121-129. [CrossRef]

11. Mukherjee, A.; Zimmerman, A.R.; Harris, W. Surface chemistry variations among a series of laboratoryproduced biochars. Geoderma 2016, 163, 247-255. [CrossRef]

12. Wiedner, K.; Fischer, D.; Walther, S.; Criscuoli, I.; Favilli, F.; Nelle, O.; Glaser, B. Acceleration of biochar surface oxidation during composting? J. Agric. Food Chem. 2015, 63, 3830-3837. [CrossRef] [PubMed]

13. Amstaetter, K.; Borch, T.; Kappler, A. Influence of humic acid imposed changes of ferrihydrite aggregation on microbial Fe(III) reduction. Geochim. Cosmochim. Acta 2012, 85, 326-341. [CrossRef]

(c) 2018 by the authors. Licensee MDPI, Basel, Switzerland. This article is an open access article distributed under the terms and conditions of the Creative Commons Attribution (CC BY) license (http:/ / creativecommons.org/licenses/by/4.0/). 